
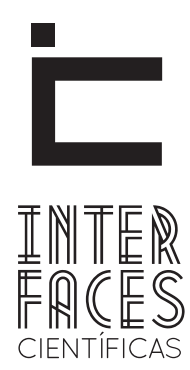

DIREITO

\title{
OS ATOS DE INVESTIGAÇ̃̃O NO INQUÉRITO POLICIAL E OS ASPECTOS DA REFORMA PROCESSUAL PENAL DE 2008
}

\author{
THE RESEARCH ACTS OF THE INVESTIGATION POLICE AND ASPECTS OF THE REFORM PROCESS PENAL 2008
}

LOS ACTOS DE INVESTIGACIÓN DE LA INVESTIGACIÓN POLICIAL Y ASPECTOS DE LA REFORMA PROCESUAL PENAL DE 2008

Vanysson Dias de Jesus ${ }^{1}$

Rony Rei do Nascimento Silva²

\section{RESUMO}

Em 2008 houve a Reforma Processual Penal, que materializou alguns dos anseios da comunidade processualista penal, porém, no tocante à matéria de provas, apesar de substancial mudança, ainda existem equívocos que precisam ser mais bem analisados. Um desses pontos, assunto principal deste estudo, é a respeito da maneira como o Poder Judiciário trata os atos de investigação oriundos do Inquérito Policial, pois o seu convencimento acerca da condenação pela prática da infração não poderá, pelo menos em tese, se valer dos elementos de informação colhidos na fase pré-processual. 0 magistrado não pode sofrer contaminação com os elementos de informação, isso prejudicaria sua imparcialidade. Caso isso ocorresse, estaria havendo uma verdadeira afronta aos primados Constitucionais e às garantias fundamentais alcançadas ao longo de todos esses anos. 0 devido processo legal, princípio constitucional, presente nos tratados internacionais de direitos humanos, estabelece as garantias que devem ser observadas em um processo. Acostadas a essas garantias estão os princípios do contraditório e da ampla defesa que definem parâmetros básicos para fazer com que a dignidade humana seja respeitada ante a crueldade de um processo penal. Pelo fato da fase investigativa ser de modelo inquisitorial, adotado pelo Código de 1941 e vigente ainda hoje, não há essas garantias mínimas da forma que a Constituição Federal estabelece. Principalmente por este motivo, o estudo bibliográfico sobre o assunto trata 
de diferenciar atos de prova de atos de investigação, onde, esses últimos produzidos em fase inquisitorial e, via de regra, sem observância do contraditório ou ampla defesa.

\section{ABSTRACT}

In 2008 there was Criminal Procedure Reform, some of which materialized proceduralist criminal complaints in the community, however, regarding matters of evidence, despite substantial changes, there are still misconceptions that need to be further analyzed. One of these points, which is the main subject of this study, it is about the way the judiciary treats the acts of investigation from the police inquiry, because its conviction about the conviction for the offense may not, at least in theory, if worth of data elements collected in the pre procedural. The magistrate cannot suffer contamination with the information, that would undermine their impartiality. If that happened, there would be a real shame to primates and Constitutional guarantees fundamental achieved over all these years. The due process of law, constitutional principle, also present in international treaties on human rights, establishes safeguar-

\section{PALAVRAS-CHAVE}

Atos de Prova. Atos de Investigação. Devido Processo Legal. Inquérito Policial.

ds must be observed in a process. Docked to these guarantees are the principles of adversarial and legal defense that define basic parameters for making human dignity is respected at the cruelty of criminal proceedings. Because the investigative phase to be inquisitorial model, adopted by Code 41 and still in force today, there is no such minimum guarantees, at least not in the way that the Constitution establishes. Mainly for this reason, the study of literature on the subject comes to differentiate acts of evidence of acts of investigation, where the latter produced in inquisitorial phase and, as a rule, disregarding the contradictory or defense.

\section{KEYWORDS}

Acts evidence. Acts of investigation. Due process of law. Police investigation.

\section{RESUMEN}

En 2008 se produjo la reforma del procedimiento penal, que se materializó algunas de las aspiraciones de la comunidad procedimental penal, sin embargo, con respecto a la cuestión de las pruebas, a pesar de un cambio sustancial, todavía hay conceptos erróneos que deben analizarse más a fondo. Uno de estos puntos, que es el tema principal de este estudio, se trata de la forma en que el poder judicial se encarga de los actos de investigación de la investigación policial se origina, por su convicción acerca de la condena por el delito no puede, al menos en teoría, si el valor de la información recopilada en la etapa procesal previa. El juez no puede sufrir contaminación con la información, que comprometa su imparcia- 
lidad. En tal caso, habría una verdadera afrenta a los primados garantías constitucionales y fundamentales logrados a lo largo de los años. El debido proceso, principio constitucional, también presente en los tratados internacionales de derechos humanos, establece las garantías que deben observarse en el proceso. Amarrados a estas garantías son los principios de la defensa contradictoria y llena de definir los parámetros básicos para que la dignidad humana es respetada por la crueldad de un proceso penal. Debido a la fase de investigación es el modelo inquisitivo, adoptada por el Código 41 y corriente hoy en

\section{INTRODUÇ̄̃O}

0 presente artigo se propõe a traçar um panorama sobre as inovações trazidas pela Lei 11.690/08, largamente conhecida como "reforma processual penal de 2008", especialmente no que se refere às provas no âmbito do inquérito policial, mais ainda, sobre a nova redação do art. 155 da Lei Adjetiva Penal, que ressalva a possibilidade do juiz valer-se unicamente das provas antecipadas, não repetíveis e cautelares produzidas em sede de Inquérito Policial para fundamentar uma condenação. Este se constitui o ponto fundamental do estudo. Para tanto, a pesquisa se sustenta, a priori, da autoridade doutrinária do Doutor Lopes Júnior e de Gloeckner (2012), cabendo a estes o auxílio na exegese do artigo supramencionado no tocante às criticas fundadas na nova redação.

Sobre os demais elementos que circundam o núcleo do estudo, a pesquisa recorre à doutrina de Lima (2011) e Capez (2011), a Oliveira (2009), Bueno (2012) e Tourinho Filho (2011) acerca das Provas em sentido amplo e, especificamente, as provas no Inquérito Policial. Com o fito de auxiliar na composição de cada capítulo, o estudo se dá por meio de pesquisa bibliográfica, jurisprudencial e, ainda, consulta legislativa. 0 artigo está estruturado em três partes, dispostas da seguinte maneira: a primeira parte intitulada " $\mathrm{Da}$ Persecução Penal" aborda a noção de investigação día, no hay tales garantías mínimas, al menos no en la forma en que la Constitución establece. Principalmente por esta razón, el estudio bibliográfico sobre el tema trata de diferenciar los actos de los actos de investigación prueba que, cuando éstas obtienen en la etapa inquisitorial y, por regla general, sin observar la defensa contradictoria o jurídica.

\section{PALABRAS CLAVE}

actos de la prueba; actos de investigación; debido proceso; investigación policial.

preliminar e a sua importância para a colheita de informações no âmbito da propositura da Ação Penal. A segunda parte levanta o tema principal deste trabaIho,: "Dos atos de investigação no Inquérito Policial e os aspectos relevantes da Reforma Processual Penal de 2008", que se preocupa em detalhar como é realizada a produção de provas nesta fase da persecução penal; e ainda sobre as sinuosidades dessa produção. Na conclusão é realizada exposição sumária dos temas abordando os principiais aspectos àqueles que tiveram mais relevância para a compreensão do estudo.

\section{EM PAUTA OS ATOS DE INVESTIGAÇ̃̃O PRODUZIDOS NO INQUÉRITO POLICIAL}

Conforme nos ensina Tourinho Filho (2011, p. 233235), a prova no Processo Penal é o meio pelo qual se demonstra a verdade dos fatos e sobre as alegações trazidas a juízo. Por isso que em direito, especialmente no Direito Penal, não é admitido que se alegue a existência de fato sem que haja uma correspondente prova para consubstanciar a certeza do que foi alegado, à exceção do que for notório e evidente, neste 
caso há a dispensa da prova, pois tanto a evidência como a notoriedade não podem ser postas em dúvida.

Segundo Lima (2011, p. 833-834) a palavra prova nos remete às ideias de verificação, inspeção, exame, aprovação ou confirmação, em outras palavras, a atividade de provas busca estabelecer o conhecimento verdadeiro. A prova está dividida em três distintas acepções:

1) Prova como atividade probatória: consiste no conjunto de atividades de verificação e demonstração, mediante as quais se procura chegar à verdade dos fatos relevantes para o julgamento. Nesse sentido, identifica-se o conceito de prova como a produção dos meios e atos praticados no processo visando ao convencimento do juiz sobre a veracidade (ou não) de uma alegação sobre um fato que interesse à solução da causa.

Nesta primeira acepção, a prova deve ser compreendida como um corolário do direito de ação, que tem previsão Constitucional ${ }^{1}$. Por este motivo não se pode admitir que as provas sejam apenas produzidas ou propostas, mas deve-se garantir que elas possam efetivamente influir no convencimento do magistrado. Devem-se assegurar às partes todos os recursos para o oferecimento da prova, sob pena de cerceamento de defesa. Porém, esse direito de provar não é de todo absoluto.

Lembra-nos Lima (2011, p. 834) que “a legitimação do exercício da função jurisdicional está condicionada, portanto, à validade da prova produzida em juízo, em fiel observância aos princípios do devido processo legal e da inadmissibilidade das provas obtidas por meios ilícitos”. Dessa maneira, a atividade probatória encontra limites dentro do ordenamento, impedindo que o juiz acolha provas que não foram produzidas sob o crivo do contraditório ou da ampla defesa e ainda que provas espúrias sejam admitidas no processo penal. Há ainda mais duas acepções da palavra prova:

2) Prova como resultado: caracteriza-se pela formação da convicção do órgão julgador no curso do processo quando à existência (ou não) de determinada situação fática. É a convicção sobre os fatos alegados em juízo pelas partes. Por mais que não seja possível se atingir

1 Art. $5^{\circ}$, inciso XXXV: A lei não excluirá da apreciação do Poder Judiciário lesão ou ameaça a direito. uma verdade irrefutável acerca dos acontecimentos ocorridos no passado, é possível atingir um conhecimento processualmente verdadeiro acerca dos fatos controversos inseridos no processo sempre que, por meio da atividade probatória desenvolvida, sejam obtidos elementos capazes de autorizar um determinado grau de certeza acerca da ocorrência daqueles mesmos fatos;

3) Prova como meio: são os instrumentos idôneos à formação da convicção do órgão julgador acerca da existência (ou não) de determinada situação fática. (LIMA, 2011, p. 834-835).

Para Oliveira (2009, p. 317) a prova deve servir para reconstruir os fatos que estão sob investigação no processo para que cheguem o mais próximo possível da verdade tal qual realmente aconteceu no espaço e no tempo. Dito isto, é possível imaginar os esforços hercúleos que devem ser dispendidos na produção de uma prova, pois a prova busca, principalmente, verdade. Por mais difícil que seja a reprodução da verdade, tal qual como aconteceu, esse deve ser um compromisso inequívoco do judiciário.

No que diz respeito ao ônus de provar, Oliveira (2011, p. 323) assevera que em sistema constitucional que garante a presunção de inocência, não admitindo que ninguém poderá ser considerado culpado senão após o trânsito em julgado da sentença penal condenatória², significa dizer, pela teleologia do dispositivo, que todo onus probrandi 3 recai sobre o órgão acusador. Por esta razão cabe ao Ministério Público ou querelante, provar a existência de um crime e, de igual sorte, provar a sua autoria. Porém, apesar de caber ao Ministério Público ou querelante provar a existência de autoria e materialidade delitiva, não se pode exigir o ônus de demonstrar a inexistência de qualquer situação excludente de ilicitude ou mesmo de culpabilidade.

O princípio da ampla de por meio de uma prova e o Estado-Juiz deve apreciá-la. É importante não olvidar que o escorreito exercício do direito à prova merece tutela em todas as fases do processo, desde a sua obtenção, passando pela introdução e produção para que ao final seja devidamente valo-

2 Constituição da República Federativa do Brasil, art. 5º, inciso LVII. 3 Ônus de Provar. 
rada pelo Estado-juiz que aplicará a decisão. Caso o magistrado deixe de observar na sentença a valoração de alguma prova que foi produzida estará configurado o erro no julgamento, cabendo reforma da decisão (OLIVEIRA, 2011, p. 331).

A Legislação Constitucional, a Lei Processual e os Princípios informadores do ordenamento jurídico pátrio vedam as provas ilícitas. Essa vedação atua no controle da regularidade da atividade estatal persecutória, inibindo e desestimulando que provas obtidas por métodos escusos possam ser produzidas por quem é responsável pela sua produção. A qualidade da prova posta em juízo deve ser pura, e a inadmissibilidade de provas ilícitas garante essa pureza ao tempo em que tutela direitos e garantias individuais. (OLIVEIRA, 2011, p. 332).

Em exemplos claros de provas obtidas por meios ilícitos, Oliveira (2011, p. 332) elenca a confissão mediante tortura, hipnose ou ainda pela ministração de substâncias químicas, que, por evidente afrontam sistematicamente garantias fundamentais como a intimidade, a privacidade e imagem, consectários do princípio maior da dignidade da pessoa humana, entabulado pela Constituição da República Federativa do Brasil.

Com sapiência ímpar, Oliveira (2011, p. 333) nos revela que a vedação das provas colhidas ilicitamente não ocorre apenas em relação ao meio escolhido para a sua obtenção, mais ainda, os resultados obtidos com essa prova devem ser considerados ilícitos também. Em outras palavras, quando uma interceptação telefônica é judicialmente autorizada, apesar de violar a privacidade ou intimidade, esta é permitida, de modo diverso, quando não é autorizada, há a clara violação dessas garantias. Portanto, em matéria de prova, mesmo que não haja vedação expressa quanto ao meio utilizado é preciso questionar se o resultado obtido configura ou não violação de direitos, e ainda se configurar, é importante questionar se essa violação foi e poderia ter sido autorizada.

Não é porque se trata de um direito do réu ter sua prova valorada que o juiz irá autorizar a produção de toda e qualquer prova. Muitas vezes o magistrado entende que não há necessidade na produção de deter- minada prova, pois já está convencido das alegações e o juiz pode indeferir as diligências que são manifestamente protelatórias (OLIVEIRA, 2011, p. 331).

A Constituição Federal repudia as provas ilícitas ou espúrias que adentram o processo, sobre o assunto:

Consequência ainda do direito à prova, ou seu reverso, porquanto dirigido ao mau exercício por parte dos órgãos da persecução penal, seria o de exclusão das provas obtidas ilicitamente, sobretudo quando se tratar de procedimentos do Tribunal do Júri. É que ali vigora a regra da íntima convicção, não se exigindo a motivação das decisões. Com isso, o contato com o material probatório ilícito poderia trazer graves consequências na formação do convencimento do jurado. Assim, tais provas deverão ser desentranhadas quanto antes dos autos, antes do ingresso na fase da valoração, nos termos, agora, do art. 157, CPP (Lei 11.690/08). (OLIVEIRA, 2011, p. 331, grifo nosso).

Conforme ensina Lima (2011, p. 884), o Estado-juiz não pode se valer das provas ilícitas para apurar um ilícito penal, isso seria, no mínimo ilógico e irracional, visto que o próprio Estado é quem garante os direitos e garantias fundamentais, caso não fosse assim, a legitimidade do Estado seria posta em xeque, pois estaria se valendo de um ilícito penal para apurar outro, o que, de fato não é congruente com o Estado Democrático de Direito ao qual nos submetemos.

É imperioso salientar que apesar da vedação expressa trazida pelo Texto Maior acerca das provas ilícitas, não é encontrada nenhuma definição para o que seriam, de fato, essas provas. Ficou a cargo da doutrina pátria buscar este conceito, que, se configura da seguinte maneira:

A prova será considerada ilegal sempre que sua obtenção se der por meio da violação de normas legais ou de princípios gerais do ordenamento, de natureza material ou processual. Prova obtida por meios ilegais deve funcionar como gênero, do qual são espécies as provas obtidas por meios ilícitos e as provas obtidas por meios ilegítimos. (LIMA, 2011, p. 885).

Quando uma prova é obtida por meio da violação de regras de direito material, ou seja, em afronta ao direito constitucional ou penal, esta deve ser considerada ilícita. Para que assim seja considerada, a viola- 
ção deve ocorrer no momento da obtenção da prova, que se dá, normalmente em momento anterior ou concomitante ao processo. Muito embora seja necessário que a prova, para ser ilícita, não possa ter sido colhida no processo, nada impede que a produção, ocorrida em sede processual, seja ilícita. Ocorre dessa maneira, por exemplo, na confissão que é colhida pelo juiz sem que este tenha alertado ao acusado acerca de seu direito de silêncio, garantido na Constituição (LIMA, 2011, p. 886).

De outro ponto, a prova ilegítima, assim considerada, é aquela produzida sem a observância das normas processuais capitaneadas em Leis Processuais Penais. É quando o magistrado instrui a produção de uma prova sem ter observado o rigor da Lei que estabelece determinados critérios para sua produção. Geralmente a prova obtida por meio ilegítimo é produzida no curso do processo (LIMA, 2011, p. 886).

\section{DAS TEORIAS: EM FOCO, AS CORRENTES "FRUTOS DA ÁRVORE ENVENENADA" E "FONTE INDEPENDENTE E DA DESCOBERTA INEVITÁVEL"}

Essa teoria, americana, deve ser entendida no sentido de que a inadmissibilidade das provas ilícitas se estenderá para aquelas provas que derivaram destas, contaminando-as e, portanto, fazendo com as demais sejam imprestáveis ao processo. Essas provas derivadas das ilícitas, apesar de formalmente produzidas de forma válida, estão envenenadas pela ilicitudes das provas originárias, vale dizer, por exemplo, que se uma autoridade policial extrair do indiciado uma confissão, usando para isso a tortura e dessa confissão chegar a outras provas que possam incriminá-lo, está perfeitamente configurada a ilicitude na prova obtida pela confissão ilícita (LIMA, 2011, p. 892).

Os frutos de uma árvore que se encontra maculada por veneno serão indubitavelmente venenosos, é dessa maneira que é entendida a teoria, que nasceu com os precedentes de famosos casos que chegaram à Suprema Corte Norte-Americana. No Brasil, a teoria sofreu rejeição pelo Supremo Tribunal Federal (STF), onde os ministros (a maioria) entendiam que a vedação entabulada no art. $5^{\circ}$, inciso LVI não se estendia às provas derivadas, mas tão somente às provas originais. Para o STF, essas provas derivadas seriam consideradas pistas, que teriam sido produzidas licitamente (LIMA, 2011, p. 893).

Sustenta Capez (2011, p. 349), acerca da teoria dos Frutos da Árvore Envenenada, que das provas colhidas ilicitamente e das que destas surgirem (com o devido nexo causalidade existente entre ambas), será inevitável a nulidade dos atos que dependeram da existência dessas provas ou que delas sejam consequência; lançando mão do princípio da proporcionalidade não se pode desprezar totalmente as provas obtidas por meios ilícitos e as que destas surgirem, principalmente pelo fato de que, em alguns casos, o interesse que se quer defender é muito mais relevante que a intimidade que se deseja preservar.

Deveria acontecer essa flexibilização do uso de provas ilícitas ou ilegítimas sempre que surgir um conflito entre princípios fundamentais elencados na Carta Magna. Neste sentido, para evitar um mal maior, isto é, uma condenação injusta ou a impunidade de indivíduos perigosos, os interesses postos no processo devem ser sopesados, acolhendo um em detrimento de outro.

A proporcionalidade aqui aventada diz respeito ao caráter excepcionalíssimo da admissão de provas ilícitas no processo penal na medida em que a regra geral de inadmissibilidade pode ser suplantada sempre que estiver em jogo um interesse de maior relevância que seja contratante com um direito ou garantia fundamental. Importa esclarecer que, em tese, não há conflito entre princípios e garantias constitucionais, já que eles se harmonizam, o que existe é um conflito aparente que deve ser resolvido pela regra equilíbrio entres valores contrastantes (CAPEZ, 2011, p. 351-352).

Esta importante teoria diz respeito às provas que são obtidas de fontes que não guardam relação de causalidade com as provas ilícitas ou maculadas por ilicitude originária. A fim de não incorrer em erro 
quanto à aplicação dessa teoria, é importante que haja demonstração inequívoca de que as provas obtidas são efetivamente oriundas de uma fonte autônoma e não estão contaminadas pelos meios ilícitos (LIMA, 2011, p. 896).

Conforme Lima (2011, p. 897), a partir da reforma processual penal de 2008, a possibilidade de utilização de provas obtidas por fonte independente das ilícitas passou a constar expressamente no texto do Código de Processo Penal, no art. $157, \$ 1^{\circ}$ onde se lê "são também inadmissíveis as provas derivadas das ilícitas, salvo quando não evidenciado o nexo de causalidade entre umas e outras, ou quando as derivadas puderem ser obtidas por uma fonte independente das primeiras".

O STF no julgamento do habeas corpus 83.921/RJ, Relator Ministro Eros Grau, DJ 27/08/2004, mesmo antes da edição da reforma processual penal já adotava entendimento no sentido de permitir as provas obtidas por meios autônomos, conforme a ementa:

HABEAS-CORPUS SUBSTITUTIVO DE RECURSO ORDINÁRIO. RECONHECIMENTO FOTOGRÁFICO NA FASE INQUISITORIAL. INOBSERVÂNCIA DE FORMALIDADES. TEORIA DA ÁRVORE DOS FRUTOS ENVENENADOS. CONTAMINAÇÃO DAS PROVAS SUBSEQÜENTES. INOCORRÊNCIA. SENTENÇA CONDENATÓRIA. PROVA AUTÔNOMA.

1. Eventuais vícios do inquérito policial não contaminam a ação penal. 0 reconhecimento fotográfico, procedido na fase inquisitorial, em desconformidade com o artigo 226, I, do Código de Processo Penal, não tem a virtude de contaminar o acervo probatório coligido na fase judicial, sob o crivo do contraditório. Inaplicabilidade da teoria da árvore dos frutos envenenados (fruits of the poisonous tree). Sentença condenatória embasada em provas autônomas produzidas em juízo. 2. Pretensão de reexame da matéria fático-probatória. Inviabilidade do writ. Ordem denegada. (HC 83921 RJ - Relator Ministro Eros Grau - DJ 27/08/2004)

Sobre o mesmo olhar, Lima (2011, p. 898) considera importante a observância do parágrafo $2^{\circ}$ do art. 157 do Código de Processo Penal no ponto em que se refere ao que seria fonte independente: "considera-se fonte independente, aquela que, por si só, seguindo os trâmites típicos e praxe, próprios da investigação ou instrução criminal, seria capaz de conduzir a fato objeto da prova". Mesmo fazendo menção ao significado da "fonte independente", observa-se pela exegese do texto legal que o legislador se referiu, mesmo que indiretamente, à teoria da descoberta inevitável, que consiste na demonstração de que a prova derivada da ilícita chegaria ao conhecimento do juízo independentemente da prova originariamente ilícita, neste caso, a prova, mesmo derivada da ilícita, deve ser acolhida, pois não guarda nenhuma ligação causal com a originária, portanto, não sofreu contaminação.

Aponta Lima (2011, p. 898), ainda sobre a descoberta inevitável, que a aplicação da teoria não pode ocorrer de forma meramente especulativa, assim como na teoria da fonte independente, é imperioso que se demonstre inequivocamente sobre a existência de dados concretos capazes de conduzir ao convencimento do magistrado acerca da descoberta inevitável. Observa-se que o Superior Tribunal de Justiça deu interpretação ao $\S 2^{\circ}$ do art. 157 do CPP no sentido de considerar que o Legislador estaria se referindo à teoria da descoberta inevitável e não à teoria da fonte independente apenas.

\section{OS ELEMENTOS DE INFORMAÇÃO: O VALOR PROBATÓRIO DO INQUÉRITO POLICIAL}

A fase de investigação preliminar, também conhecida por Inquérito Policial, que compõe a persecução penal, é encargo da Polícia Judiciária e também do Ministério Público (Princípio dos Poderes Implícitos)4, mas não é encargo do juiz. Conforme assevera Oliveira (2019, p. 325), “o juiz não tutela nem deve tutelar a investigação". Nem mesmo quando o juiz defere uma interceptação telefônica ocorrida na fase de Inquérito

4 Ora, é princípio basilar da hermenêutica constitucional o dos 'poderes implícitos' segundo o qual, quando a CF concede os fins, dá os meios. Se a atividade fim - promoção da ação penal pública - foi outorgada ao Parquet em foro de privatividade, não se concebe como não the oportunizar a colheita de prova para tanto, já que o CPP autoriza que 'peças de informação' embasem a denúncia. Cabe ressaltar que, no presente caso, os delitos descritos na denúncia teriam sido praticados por policiais, o que, também, justifica a colheita dos depoimentos das vítimas pelo Ministério Público" (HC 91.661, Rel. Min. Ellen Gracie, julgamento em 10-3-2009, Segunda Turma, DJE de 3-4-2009.) 
Policial, ele não estaria tutelando os interesses da investigação criminal e sim, tutelando as liberdades públicas, fazendo o controle constitucional das restrições às inviolabilidades, nos limites da Constituição Federal.

É patente que os elementos de informação colhidos no calor dos acontecimentos da fase investigatória, prescindem de contraditório e de ampla defesa e que estes não poderão, à revelia do primado do devido processo legal, servirem unicamente para que o juiz conduza uma sentença condenatória. É a cabeça do artigo 155 do Código de Processo Penal (LIMA, 2011, p. 116-117):

O juiz formará sua convicção pela livre apreciação da prova produzida em contraditório judicial, não podendo fundamentar sua decisão exclusivamente nos elementos informativos colhidos na investigação, ressalvadas as provas cautelares, não repetíveis e antecipadas.

Que foi substancialmente alterado pela Lei 11.690/2008, onde se tinha a seguinte redação: “Art. 155. No juízo penal, somente quanto ao estado das pessoas, serão observadas as restrições à prova estabelecidas na lei civil".

Neste ponto, merece a crítica instruída por Lopes Jr (2008):

0 art.155 não teve coragem para romper com a tradição brasileira de confundir atos de prova com atos de investigação, com graves reflexos na eficácia probatória deles. A redação vai muito bem, até o ponto em que inseriram a palavra errada, no lugar errado. E uma palavra, faz muita diferença... Bastou incluir o "exclusivamente" para sepultar qualquer esperança de que os juízes parassem de condenar os réus com base nos atos do famigerado, inquisitório e superado inquérito policial. (LOPES JUNIOR, 2008, p. 9).

Com efeito, Lopes Jr e Gloeckner (2013, p. 206) distinguem atos de prova (produzidos em fase processual) de atos de investigação (produzidos em sede de Inquérito Policial) ao passo que:

Sobre os atos de prova podemos afirmar que:

a) Estão voltados a convencer o juiz da verdade de uma afirmação; b) Estão a serviço do processo e integram processo penal;

c) Dirigem-se a formar um juízo de certeza - tutela de segurança;

d) Servem à sentença;

e) Exigem estrita observância da publicidade, contradição e imediação;

f) São praticados ante o juiz que julgará o processo;

g) Sujeitam-se aos requisitos normativos, aplicando-se-lhes a teoria dos atos processuais defeituosos (teoria das nulidades);

Substancialmente distintos, os atos de investigação (instrução preliminar):

a) Não se referem a uma afirmação, mas a uma hipótese;

b) Estão a serviço da instrução preliminar, isto é, da fase pré-processual e para o cumprimento de seus objetivos;

c) Servem para formar um juízo de probabilidade, e não de certeza;

d)Não exigem estrita observância da publicidade, contradição e imediação, pois podem ser restringidas;

e) Servem para a formação da opinio delicti do acusador;

f) Não estão destinados à sentença, mas a demonstrar a probabilidade do fumus commissi delicti para justificar o processo (recebimento da ação penal) ou o não processo (arquivamento);

g) Também servem de fundamento par decisões intelocutórias de imputação (indicamento) e adoção de medidas cautelares pessoais, reais ou outras restrições de caráter provisional;

h) Podem ser praticados pelo Ministério Público ou pela Polícia Judiciária;

i) De acordo com a jurisprudência e doutrina dominantes, não se sujeitam ao controle de validade próprio dos atos processuais (nulidade), [...].

Conforme se extrai dessa cadeia de diferenças existentes entre os atos de prova e os atos de investigação, é perfeitamente perceptível a fragilidade que rodeia os atos de investigação (indícios ou elementos de informação). 0 que se pode admitir é a verdade processual produzida numa relação dialética entre o magistrado, o órgão acusador e a defesa, com a plena e irrefutável presença do devido processo legal estampado pelo contraditório e pela ampla defesa. Em curta síntese, os atos de investigação deveriam servir apenas às decisões 
interlocutórias que se produzem no curso da instrução preliminar e na fase intermediária. E mais, servirão também como embrião para o nascimento da ação penal ou o seu não nascimento, no caso dos elementos não tiverem força o suficiente para propagar este nascedouro, neste caso, fica à convicção do Ministério Público ou querelante (LOPES JR; GLOECKNER, 2013, p. 208).

Consoante Carnelutti (2002) as provas produzidas durante a fase de investigação preliminar deverão servir apenas aos fins desta investigação. Os elementos de convicção do magistrado não podem ser outros senão àqueles que ocorreram na sua presença, ou seja, os que ele viu e ouviu, dispensando quaisquer outros elementos que foram colhidos sem a sua ingerência.

Segundo Lopes Jr e Gloeckner (2013, p. 209) o Brasil está vinculado à Convenção Americana Sobre Direitos Humanos, que assegura uma série de garantias judiciais, dentre elas a publicidade, o contraditório e a ampla defesa que devem ser observados nos processos. Os atos de investigação tem eficácia limitada pela forma como são praticados, isto é, por meio de um sistema inquisitório, onde prevalece o sigilo, forma escrita e ausência ou quase ausência de contraditório. Diante da ordem constitucional vigente é inconcebível que atos de investigação, colhidos por uma autoridade administrativa, não investida em jurisdição, possam ter valor probatório na sentença. Além disso, os atos de investigação preconizam o caráter inquisidor da acusação, pois o contraditório, muitas vezes, é meramente aparente e muitas vezes absolutamente inexistente.

Em suma, os atos de investigação devem ter função endoprocedimental, isto é, sua eficácia probatória deve restringir-se à fase de inquérito policial. De fato, acertada é a posição adotada pelo sistema italiano, quando permite que sejam eliminados dos autos do processo, todas as peças da investigação preliminar, à exceção do corpo de delito e das provas antecipadas que serão produzidas no incidente probatório (LOPES JR; GLOECKNER, 2013, p. 210).
Importante transcrever a seguinte dicção acerca dos atos de informação e a Reforma Processual Penal de 2008:

No Brasil, a reforma do processo penal de 2008 tratou da restrição probatória dos atos de investigação. Entretanto, através de uma tímida limitação perdeu-se a oportunidade de chegar ao status de uma verdadeira barreira processual quanto à utilização dos atos da investigação preliminar. Refere o art. 155 do Código de Processo Penal que "o juiz formará sua convicção pela livre apreciação da prova produzida em contraditório judicial, não podendo fundamentar sua decisão exclusivamente nos elementos informativos colhidos na investigação, ressalvadas as provas cautelares, não repetíveis e antecipadas". Como se pode perceber, apesar da aparência de melhoria do sistema, a fim de se evitar a constante e reiterada utilização das informações do inquérito policial na sentença, pensamos que o art. 155 não apenas não evoluiu rumo à restrição à fundamentação da sentença como legitimou a sua utilização, desde que em cotejo com os demais elementos colhidos em contraditório; [...] (LOPES JR., 2013, p. 211-212).

A compreensão da crítica externada por Lopes Jr e Gloeckner (2013, p. 212) se funda, principalmente, pela inadmissibilidade de uma interpretação literal do disposto no art. 155 do CPP5, que dá azo a uma utilização velada dos elementos de informação que compõem o inquérito policial, que justapostos a outros elementos contidos no processo seriam capazes de fundamentar uma sentença condenatória. 0 mínimo que se exige de um Estado voltado para as tutelas das garantias individuais e coletivas é que tenha magistrados desprovidos de juízo de valor pré-formulados. Esses pré-juízos são um resquício do sistema inquisitório que, apesar de não ter ser sido expurgado do ordenamento pela ocasião da reforma processual penal de 2008, não poderá contaminar o processo. Caso isso ocorra, fragilizaria todo um sistema de garantias conseguido à duras penas.

A respeito da reforma processual de 2008 , especialmente na estrutura do novo artigo 155 do Código de Processo Penal, a proposta da Comissão seria a vedação em absoluto da utilização dos atos de investigação na formação da convicção do magistrado, porém,

5 Código de Processo Penal. 
- Legislador optou por inserir a palavra "exclusivamente" no corpo do artigo, o que o tomou uma lógica diferente da proposta inicial. Com a presença dessa palavra, a interpretação surge da seguinte maneira:

[...] ao introduzir na nova redação do art. 155 do CPP o advérbio exclusivamente, a Lei 11.690 permite que elementos informativos da investigação possam servir de fundamento ao juízo sobre os fatos, desde que existam, também provas produzidas em contraditório judicial. (GOMES FILHO, 2008, p. 251).

Em outras palavras, com a mudança introduzida no artigo, é possível o juiz utilizar-se dos atos de investigação a fim de obter afirmação sobre um fato, mas sob a condição de que existam provas produzidas em contraditório judicial que sejam capazes de confirmá-las. Exemplificando o contexto:

[...] na situação em que as informações do inquérito policial apontem para a ocorrência de um furto qualificado. Se as provas produzidas em contraditório judicial somente confirmarem a subtração, mas nada disserem sobre a qualificadora, em relação a esse último fato, não haverá convergência e, portanto, o juiz não poderá sobre ele formar o seu convencimento exclusivamente com base nas informações do procedimento investigatório. (GOMES FILHO, 2008. p. 252).

Segundo Lopes Jr e Gloeckner (2013, p. 213), isso não poderia acontecer em um Estado de Garantias como o nosso, muito embora, a informação que guarnece o procedimento investigatório preliminar somente pode ser utilizada quando preenchidos os requisitos de judicialidade que nascem da produção cautelar de provas, e não a simples "convergência" entre os elementos de informação e a prova judicial. O que escapar dessa linha deverá ser descartado, pois inservível às garantias fundamentais e fulminador do devido processo legal.

\section{CONSIDERAÇÕES FINAIS}

A reforma processual penal de 2008 trouxe significativos avanços ao Direito Processual Penal e em linhas mais específicas, no que diz respeito à disciplina das provas no processo. Porém, a proposta maquinada pela comissão de juristas definitivamente não coaduna com a resposta legislativa trazida pela Lei 11.690/08 pelo menos em parte, conforme a crítica trazida à lume nesse estudo bibliográfico, jurisprudencial e legal.

0 inquérito policial é, a priori, o mecanismo que o Estado se utiliza para buscar os indícios de autoria e materialidade detilitiva, a fim de subsidiar a futura ação penal. Trouxemos que se trata de um procedimento administrativo que é dispensável à propositura da ação penal, muito embora, essa característica de dispensabilidade pouco se observa na prática. Em tese, há a dispensabilidade, de modo que o autor da ação penal (Ministério Público ou querelante) pode se valer de outros meios para dar inicio à ação, não precisa ficar atrelado ao inquérito.

0 que deve ser considerado é que a maioria das infrações penais que chegam ao judiciário são pela via do inquérito policial, que, destaque-se, tem natureza inquisitória, isto é, os atos de investigação colhidos "ao calor dos acontecimentos", dispensam, via de regra, a presença do contraditório e da ampla defesa, princípios fundamentais no processo penal em defesa do devido processo legal e da dignidade da pessoa humana.

Muito embora seja dessa maneira que o inquérito é produzido, notamos, no decorrer do estudo, que essa "maneira" desumana e cruel de investigar a prática de crimes vem perdendo espaço, pelo menos no cenário internacional. Entendemos que não se pode condenar unicamente com as provas que são produzidas no inquérito policial, fizemos a crítica específica ao termo "exclusivamente" utilizado no caput do art. 155 do CPP, já que essa possibilidade dá margem a uma interpretação de que o magistrado poderia corroborar as provas produzidas no processo e cotejá-las com os indícios trazidos do inquérito policial. Consideramos a possibilidade acolhida pela doutrina italiana, que prevê o completo desentranhamento dos autos do "inquérito" da fase processual, já que o este instrumento deveria servir apenas ao MP ou ao querelante no sentido de propor a demanda penal. 


\section{REFERÊNCIAS}

BUENO. Cassio Scarpinella. Curso sistematizado de direito processual civil, 4: tutela antecipada, tutela cautelar, procedimentos cautelares específicos. 4.ed. rev., atual. e ampl. São Paulo: Saraiva, 2012.

CAPEZ, Fernando. Curso de processo penal. 16.ed. São Paulo: Saraiva, 2009.

\section{CARNELUTTI, Francesco. As misérias do processo} penal. Tradução de José Antonio Cardinalli. Campinas: Edicamp, 2002.

GOMES FILHO, Antônio Magalhães. As reformas no processo penal: as novas Leis de 2008 e os projetos de reforma - Coordenação Maria Thereza Rocha de Assis Moura. São Paulo: Revista dos Tribunais, 2008

LEITE, Ruano Fernando da Silva. Princípio do contraditório. Disponível em <http://www.jurisway. org.br/v2/dhall.asp?id_dh=754>. Acesso em: 28 nov. 2012.

LIMA, Renato Brasileiro de. Manual de processo penal. V. I. Niterói, RJ: Ímpetus, 2011.

LOPES Jr., Aury, GLOECKNER, Ricardo Jacobsen. Investigação preliminar no processo penal. 5.ed. rev. atual. e ampl. São Paulo: Saraiva, 2013.

LOPES JUNIOR, Aury. Bom pra quê (m)? Boletim do IBCCRIM, ano 16, n.188, julho 2008. p.9.

OLIVEIRA, Eugênio Pacelli de. Curso de processo penal. 11.ed. Rio de Janeiro: Lumen Juris, 2009.

TOURINHO FILHO, Fernando da Costa. Processo penal. V.I. 33.ed. rev. e atual. São Paulo: Saraiva, 2011.
1 Mestrando em Direito pela Universidade Federal de Sergipe - UFS; Especialista em Processo Civil. Bacharel em Direito pela Universidade Tiradentes com inscrição nos Quadros da OAB/SERGIPE;Membro dos Grupos de Pesquisa História, Memória, Educação e Identidade - GPHMEI. E-mail: vanysson@msn.com

2 Doutorando em Educação pela Universidade Estadual Paulista “Júlio Mesquita Filho" - UNESP; Mestre em Educação pela Universidade Tiradentes - UNIT (2016) com Bolsa Capes/FAPITEC/SE; Graduado em Serviço Social pela Universidade Tiradentes - UNIT (2014); Pesquisador do Grupo de Pesquisa Serviço Social e Sociedade, membro dos Grupos de Pesquisa História, Memória, Educação e Identidade - GPHMEI e Sociedade, Educação, História e Memória - GPSEHM. E-mail: ronysocial@hotmail.com 
